\title{
Social Representations and Individual Representations: What is the Difference? And Why are Individual Representations Similar?
}

\author{
Saadi Lahlou \\ London School of Economics and Political Science, \\ Houghton St, London, WC2A 2AE, United Kingdom of Great Britain and Northern Ireland \\ Paris Institute for Advanced Study, \\ 17 Quai d'Anjou, Paris, 75004, French Republic
}

S.Lahlou@1se.ac.uk

\begin{abstract}
This paper clarifies a long-standing ambiguity in the notion of social representations; it provides a clear operational definition of the relation between social representation and individual representation. This definition, grounded in the theory of sets, supports most current empirical investigation methods of social representations. In short, a social representation of an object in a population is the mathematical set of individual representations the individuals of that population have for this object. The components of the representation are the components used to describe this set, in intension in the mathematical sense of the term (in contrast with a definition in extension). Statistical techniques, as well as content analysis techniques, can construct such components by comparison of individual representations to extract commonalities, and that is what classic investigations on social representations indeed do. We then answer the question: how come that, in a given culture, individuals hold individual representations that are so similar to one another?
\end{abstract}

Key words: social representations, individual representations, installation theory, intersubjective understanding of objects

\section{The intersubjective understanding of objects}

Experience shows that members of a population each hold similar individual representations of many "objects" of their culture. By "objects", I mean material objects (chairs, bottles...), material compounds of "things that move together" (a suit, a fleet ...), conceptual objects (space, time, democracy...) and even heterogeneous compounds that "go together" (city, hospital, dinner...). This can be easily checked: people are able to name objects properly ("this is a chair"), cooperate locally using indexicals ("pass me the salt please") or even communicate complicated arrangements of complex objects (e.g. "discharge this patient from the hospital tomorrow"). 
So, (1) we are able to connect a phenomenon external to our mind (the "object") to a mental structure internal to our mind (the "representation") that matches the object in some structural or functional manner, such that the representation will enable recognition of the object and acting upon it in a relevant manner, and (2) for a given object, different individuals in each culture appear to each hold similar representations, to the effect they can communicate and act in a relevant manner about that object.

Let us call this phenomenon (empirical facts $1+2$ above) the intersubjective understanding of objects as we need a shorthand to discuss the nature of social representations. That Intersubjective Understanding of Objects (IUO) is not merely about communication. It comes with the constructivist assumption that participants refer to "the same Object". When I say "pass me the salt" to my neighbor at the dinner table, we both assume that we talk about this little container of white powder on the table. That seems obvious. Now if I tell my neighbor in the voting line "please vote for the best candidate for democracy" we realize that the agreement on "What You Think is What I Think" is not so trivial, since my predicate "best candidate for democracy" can refer to different objects of the world for me and my fellow citizen in the voting line. Still, intersubjective understanding works well enough for most everyday objects; and therefore this" psycho-social pact" that "What you See is What I See" ("the implicit agreement by which the Participants agree that their respective individual views refer to a single object" (Lahlou, 2006)) is at the root of our social construction of reality, and of the naïve realism that is the implicit assumption behind our everyday life interactions.

While the above IUO may appear obvious as an empirical fact, in practice that means members of a culture each individually house "similar" mental representations for thousands of "objects"; that is remarkable and a priori improbable. This improbable fact nevertheless grounds our capacity to act as members of a culture, grounds the IUO. How come we different individuals have similar representations? This problem of "common knowledge" and "common sense" has been theorized extensively by Serge Moscovici and his school, with the concept of "social representations" since his seminal work (Abric, 1994; Doise, Palmonari, 1986; Duveen, Lloyd, 1990; Farr, 1987; Flament, 1994; Herzlich, 1969; Jodelet, 1989b, 1991; Moscovici, 1961, 1976).

Social representations are:

- "a form of practical knowledge linking a subject to an object" (Jodelet, 1989a; my translation. - S.A.);

- "it is a form of knowledge, socially elaborated and shared, with a practical aim and contributing to the construction of a reality common to a social set" (Jodelet, 1989a; my translation. - S.A.).

These definitions highlight that a social representation has an object, and a population of subjects using this representation in intentional manner regarding that object.

To facilitate the discussion below, let us fix a few definitions:

- the Object of representation is what the representation "is a representation of": in practice what the representation stands for in thought or communication. E.g., the Object of "the representation of psychoanalysis" is: psychoanalysis;

- the Population is the set of individual subjects who use this representation. 
The representation appears "social" in two aspects: in its genesis, as it is socially constructed, and also in that IUO property described above, that it seems, empirically, to be "common" to all members of a Population who can identify it as such in practice ("this is the Object!"). In practice, IUO can be built into an empirical test that members of a Population refer to the same Object (Moliner, 1993).

The phenomenon that members of a culture apparently give the same name to the same "thing", or connect the same Object to their individual representation, has often been described as members of a culture "sharing" representations. In fact, individuals do not "share" the representations, they each merely host similar individual representations, just as two people wearing the same model of shoes do not "share" their shoes: they merely each own similar shoes.

Alas the seminal texts on social representations failed to address the ontological issue clearly: there seemed to be no ontological difference between social representations and individual (mental) representations. In fact, reading them one could assume that social representations were a specific type of individual, mental, representation: the ones that were "shared", and by this we should understand that each individual would house his or her own exemplar of "the" social representation, just like at some point in history each good Chinese citizen would have his/her own copy of Mao's little red book. This seems acceptable if every individual would hold the exact same representation. Then there would be no need to distinguish individual representation from social representation.

But this it does not fit with the empirical evidence. Different persons do hold slightly different individual representations of the Object. This seems at first a detail, but the devil is in the detail. Because what is not exactly identical is ontologically different. So, would there be as many social representations as there are individuals in the Population? Henceforth we do not know what "social representation" we talk about if there are many different ones. Researchers using the social representations concept have all, including from the very start Moscovici himself, been confronted to that problem.

\section{Individual differences in representation}

To clarify, let us look more closely at the empirical process of studying social representations. To analyze social representations (SR) of the Object, what we collect are individual representations (IR) of the Object. Typically, members of the Population are asked to describe the Object, through interviews, questionnaires or some other device. The social representation is then usually considered what is "common" to those discourses collected. Indeed, usually there are many similarities between the material collected on the various individuals. There are also some differences. The empirical finding that individual versions of a social representations are somewhat different must be accounted for since individuals are supposed to have "the same" social representation. This generated a series of theoretical responses which were operational in practice but, as I argue below, are epistemically inappropriate.

Moscovici was the first to encounter the problem of differences in IR. He addressed that issue by considering there are different types of social representations, depending on their stage of development. The representations can be Hegemonic, 
Emancipated or Polemical (Moscovici, 1988), depending on the degree of consensus (in practice: of similarity) of individual representations of the Object among the Population. Remember the theory initially addressed unfamiliar Objects that would be made familiar through the construction of a social representation. For example, when a new Object enters the social field (e.g. Psychoanalysis, AIDS) there might be some conflicting views in different segments of the Population, hence several competing versions of the ("polemical") social representation. But in the end, when the social group has reached some consensual view, the representation may become hegemonic (everybody has the same IR). So, the differences would simply account for SR in the making, fully bloomed SRs would be hegemonic: everyone hosts the same.

But in fact, there always remain some differences in a Population regarding an Object, especially according to socio-economic status. Willem Doise came up with the notion of position taking (Doise, 1986) regarding the Object ("prises de position"): this may account for the fact that in practice we collect different versions from different subjects, even for Objects that have been around for a long time. In other words, for the problem at hand here (but of course that is a caricatural interpretation of Doise's excellent work which sheds important light on the nature of representations) there would be different representations because there are different Populations, each having its own perspective. Still, as in the detail everyone hosts a slightly different representation, there would be in full rigor as many Populations as individuals?

Another empirical issue occurred. It turns out that even the same person can mobilize different IR of the Object in different circumstances. For example, one might exhibit a scientifically correct representation but, in some cases, use another one (e.g., magical, religious, traditional, etc.) To address this issue, Moscovici, in his seminal book on social representations, came up with the notion of "cognitive polyphasia" (Moscovici, 1976. P. 282): the idea that different kinds of knowledge, possessing different rationalities can coexist in an individual or a population. That notion, while locally dealing with the empirical facts, raises serious epistemic issues: if there is polyphasia, which of the various versions "is" the social representation? Or are there different objects? Interestingly, Moscovici writes a series of caveats about the limitations of theories in general ${ }^{1}$ and suggests that much research remains to be done on social representations.

Finally, it was noted empirically that the representations that are given explicitly by people are in some cases not exactly what they think. Respondents tend to give investigators "politically correct" versions of the representation - a case of the desirability bias, and more generally of the responses bias where respondents tend to tell the researcher what they think the researcher wants to hear (Rosenthal, 1966). For example, respondents would not make explicit that their representation of the unemployed people includes laziness. Abric and collaborators described this as the "mute zone" of social representations (Abric, 2003a). This draws our attention to the idea that what we observe empirically are IR expressed by indi-

1 "Une théorie ne recouvre jamais les données empiriques. Elle est débordée et les déborde" (Moscovici, 1976. P. 289). 
vidual subjects, while "social representations" are a research construct, designed to address the phenomenon of mutual social understanding (IUO).

In short, the assumption has usually been made that the observables (subjects' discourse) are of the same nature as the construct (social representation). This assumption is not explicit in the literature; but it is clear, from the way the empirical material (usually discourse, or items of discourse) is collected, analyzed, and directly used into the description of the social representation, that we act as if these two entities (IR expressed by subjects, and SR constructed by the researcher) were made of the same epistemic fabric. I will argue here that it is not the case.

\section{A formal definition of social representations, and two ways they can be described}

As noted above, there is ambiguity in the core texts regarding the epistemic status of social representations; this has been noted many times, right from the early days of the theory's success (Billig, 1988; Jahoda, 1988; McKinlay, Potter, 1987; Potter, Edwards, 1999; Potter, Litton, 1985; Potter, Wetherell, 1987). The lack or formalism in the definitions allows looseness in the discussion. The confusion between individual and social representation has been detrimental to the advancement of the theory. So let us clarify here.

An Individual representation (IR) of an Object $\mathrm{O}$ is a symbolic structure that an individual subject uses to deal cognitively with the Object. This structure "stands for" the Object in thought, communication and action. A representation can be embodied (in the form of neural network); it can be projected onto some medium or support (speech, writing, drawing), etc.

$A$ Social representation (SR) of an object $O$ in the population $P$ is the set of individual representations of $O$ in the population $P$. E.g., the social representation of "Contraception" in the UK will be the full set of all IR of what contraception is for the members of the British population (a set of more than 60 million IR).

IR and SR are different in nature and logical type. IRs are included in the SR, but the SR is not an IR. A set cannot be an element of itself. So, no individual can "have" a SR, individuals can only have IRs.

Still, as IRs of a given Object in a Population tend to be similar, each individual usually does hold an IR that has characteristics similar to the modal or the mean IRs in the population. I. e. the components of that specific individual's IR will usually be similar to those of the other individuals in the population. E.g. most individuals in the population will know that "contraception" has something to do with avoiding reproduction when having intercourse, and most people will be aware of the usual means for this (pill, condoms etc.) But there will be individual variations in knowledge and attitude, and variations in practice, between individuals and even for a given individual according to circumstances; there will also be variations in what people say about it and likely there will be some mute zones (e.g. depending who subjects talk to); etc.

So how can we describe social representations properly? Mathematically, in the theory of sets (Cantor, 1874; Halmos, 1974; Runde, 2005) a set can be described in intension or in extension. An intensional description defines a set by 
some properties (predicates) of its elements (usually a rule or semantic description; necessary and sufficient conditions). E.g. an intensional definition of "Birds" could be "Animals with wings": $\{\mathrm{x} \mid x \in$ Animals: $x$ has wings $\}$. An intensional definition of the clients of a Bank B would be the list of holders of an account in that bank $\{x \mid x$ has an account in Bank $B\}$.

An extensional definition explicitly lists all the individual elements of the set. An extensional definition of the clients of a bank would be the listing of all the names of these clients. Extensional definitions are accurate and explicit, nevertheless they usually (unlike for the Bank B case above) become impractical for large sets. E.g., an extensional definition of birds would be the (very long) list of all the individual birds on the planet (millions of individuals).

\section{The problem with describing social representations}

Social representations, as any set, can be defined in intension or in extension. In practice, because of the huge size of the sets of human Populations, SRs are defined in intension. This definition is empirically obtained through statistical techniques, by inferring the properties of the social representation from a sample of the set.

Individual mental representations are observable empirically, for instance by asking a sample of individuals to talk about the object (e.g., "If I tell you 'Democracy', what comes to your mind?"). From this sample one extracts (through content analysis) a description of the elements of the set of IRs. Then one infers statistically the intensional definition of the set. For example, the SR of "Studying" is found by (Lheureux et al., 2008) to contain the following cognitive components: Knowledge, Investment, Diploma, Culture, Future, Work, Job, Long term, University; this is obtained through questionnaires filled in by a sample of students. The set (SR) can then be described in intension by these components which are characteristic of the elements (IRs) of the set.

What is tricky is that, when we describe the SR, we use words to refer to content traits, just as we do use words when we describe IRs. For example: "Knowledge", "Diploma", "Culture", "University" are typical components of individual representations of "Studying"; and it is the same words we use to describe the components of the social representation of Studying. This is dangerous because there is a difference in logical type (Russell, 1908; Whitehead, Russell, 1962) between IR and SR; and making confusions between logical types brings errors and paradoxes.

If we do not distinguish properly, with the right formalism, between the element (IR) and the set (SR), we may attribute to the SR (the set) properties that lay in the element (IR), and vice-versa. While for some properties that is not problematic, for others that is a recipe for disaster. Rom Harré aptly spotted the issue in a critic of social representation theory (Harré, 1984):

"The weight of an army is a distributive property, while its organization is a property of the collective. As far as I can see, the concept of représentation sociale is used by the French school as a distributive property of groups".

Let us illustrate with the analogous problem of the biological species. We could account for the fact that in the species of Dogs there are small and big 
dogs by saying that the species is Polemical and not Hegemonic, or account for the fact that not all dogs bark when observed by calling "barking" a mute zone of the species, etc. But describing the Dog species as a population is a more rigorous approach because it acknowledges the various factors of diversity in the population. We do not need to invent names of properties for the Dog species (the set) to account for the distribution of some individual characteristics (e.g., size) across elements of the species (individual dogs).

Defining social representations as the set of individual social representations is a clean epistemic solution to the problem of the relation between IR and SR. Interestingly, this theoretical clean-up has little practical implication on the way social representations research is done, because researchers have in their empirical practice always acted as if the SR is a set of IR.

Indeed, as said above, when a set is described, it is done so usually in intension as the list of common properties of the elements of the set ("a Mammal", "that barks", etc.). And in practice social representation specialists do indeed extract these common properties by comparing individual representations. That is precisely extracting a representative sample of the set of individual representations - implicitly acting as if the social representation was that set- and then finding commonalities of the elements of that set, to infer an intensional definition of the set based on these commonalities.

Nevertheless, this clarification has theoretical implications, and considering SR as sets it is necessary to take an evolutionary perspective (Lahlou, 2015). Indeed it is through the variation of individual representations that the social representation evolves, just as a natural biological species (e.g. Finches) evolves as a population through the variation of individuals. That is why this new definition, which is operational in practice and epistemically appropriate, should be used. It is also, as we'll hint below with the theory of the medium (Bachimont, 2004), essential to understand how the characteristics of the individual influence the operation of the representation and its processing into action.

In passing, our definition clarifies in terms of statistical distribution what are the different types of social representation - hegemonic vs polemical etc. In hegemonic representation the set has little variance, while in polemical representations there will be subsets of the population that are homogeneous as a subset but differ markedly from the other subsets. And for "cognitive polyphasia": a given individual can have several IRs of the "same" Object, which they use alternatively according to the circumstances in which the Object appears (e.g., the same person might use different contraception methods depending on the situation).

\section{A social representation is more than a set of similar representations}

The theory of sets brings us useful formalism to distinguish the nature and logical type of social vs individual representations. Nevertheless it does not do justice to what a SR is: a SR is more than a set of similar IR. It gathers IR that are linked both functionally (to their Object) and socially (to their Population).

The IRs that constitute an SR emerged to facilitate action and communication about an Object of the life-world, among a specific population (e.g. how British people should deal with contraception, how students and teachers should deal 
with education, etc.) That is the intersubjective understanding of objects (IUO) alluded to in introduction. Therefore, those IR of the same SR all point to the same empirical phenomenon "out there" and their content is designed for operational effectiveness of the representation, for practice and communication. Simply said, representations must "match" reality well enough to enable the Population to deal efficiently with the Object.

IRs are not independent of each other within the Population. In practice, as members of the population communicate and cooperate, their IRs crossbreed: there is discussion, controversy, influence, education. That stirring facilitates homogeneity of the set of IRs.

These two aspects (functional and social) are intertwined because practice is a social process. In society, people communicate-and-act all-together-in-the-samemovement.

To sum up, a SR is a set of IRs which are linked together because they refer to the same Object in a given Population. They are connected together by the social practice of that Object in that Population, and they are linked to the Object and the Population by the process of social construction of the Object, by which practice continuously reconstructs the Object.

There is inevitably variability between the IRs, within individuals and across individuals. The variability reflects the different practices which different members of the population have with the object, across time and space. Still this variability is limited by the functional constraints of practice and communication, as those who actually co-interact with the object must have a minimum of common ground to interact. These functional restrictions ensure the coherence of the SR into more than a random set of similar IRs. That is why SR differ from "memes" (Dawkins, 1976), and more generally why Social Representations theory is different from the naïve approach of "shared" representations, which considers a set of multiple replicated occurrences of a single representation, "copies" distributed over a population.

That was a clarification of what has for too long being ambiguity in the theory. Defining social representations as sets of IRs is consistent with the very spirit of the concept. In fact, as noted above, all the empirical work on social representation is implicitly based on the idea that a social representation is a set, of which the characteristics are obtained by sampling elements (individual representations) from that set, and describing their characteristics based on what traits they have in common, which is typically the process of describing a set in intension. Retrospectively, the definition of SR as sets of IRs provides solid epistemological ground for all techniques that describe SR based on surveys on samples of IR in fact the immense majority of the studies in the field. So, we do not have to throw out the baby with the bathwater: most empirical work on social representations lays on solid epistemic ground - even though the theory was ambiguous.

\section{Why individual representations are similar?}

Now we have a proper definition of a SR, we can address the question behind the intersubjective understanding of objects: how come that, in a given culture, individuals all hold individual representations that are so similar to one another? 
Individual representations can be learned by education, by communication and by practice. In the two first cases, it is obvious that representations are in some way replicated from one individual to another, and therefore will be similar, albeit minor losses in translation. Diffusion of IR through these mechanisms accounts for similarity between individual representations among members of the same culture (Lahlou, 1996; Sperber, 1996).

But that does not cover all cases. Individuals who have never communicated may have similar representations. Furthermore, mere communication only provides theoretical knowledge of the object; but in many cases direct experience is necessary to support actual practice, as is well known in instruction and training. Let us now look at construction of representations through practice.

The relation of representation to practice is (under various names and guises) a major topic in social science. Let us try to summarize in a paragraph what we know. In society, practices and representations reproduce each other (Berger, Luckmann, 1966; Bourdieu, Passeron, 1977; Giddens, 1984). During social interaction, individuals learn to behave properly (Goffman, 1974; Mead, 1972; Rogoff, 2003; Schütz, 1944). They acquire a common knowledge and skills, about local practices, typical of a culture (Abric, 1994; Bruner, 1999; Durkheim, 1898; Foucault, 1978; Jodelet, 1989b; Moscovici, 1961; Vygotsky, 1986). This knowledge is embodied in individuals and expressed in symbolic form (Barsalou, 2003; Freud, 1895; Karmiloff-Smith, 1992; Lashley, 1951). Then, once embodied, in situation knowledge and skills, combined with mediating structures distributed in context, produce practices (Barker, 1968; Cicourel, 1992; Hutchins, 1995; Maturana, Varela, 1980; Pea, 1993; Suchman, 1987).

As we see, the (re)production of representations involves the context and action in context; so that is where we must look for an explanation beyond education and communication.

The short answer to our question is that members of a given Population hold similar representations because they interact with similar objects (those objects that make the life-world of that Population). But furthermore there are mechanisms that channel individuals to learn, through similar practice, similar representations.

Indeed, we could assume that, by trial and error, every individual would gradually construct, of a given Object, its own IR of that Object. Then, as all members of the Population interact with the same object, they would in the end converge. But trial and error is a slow process, and convergence is not guaranteed. Anyway, investigation shows that is not how things are done. There are socially constructed devices, "installations", which channel behavior of members of a given population into predictable, typical, sequences. These installations include material affordances that guide action and social mechanisms of feed-back that reward those who use "proper" representations vs "improper" ones.

\section{Installation theory}

In society, individual behavior is predictable. Full grown members of a Population know how to behave in standard social situations such as "a dinner", "at the dentist", "a flea market", "a shower", "an election", "a tribunal", "a wed- 
ding", "a conference", etc. Sometimes we only know approximately, but when in situation the context and other people give us enough scaffolding and feed-back to channel us into the proper behavior. Let us call installations the specific, local, societal settings where humans are expected to behave in a predictable way (a dinner, an election, etc.)

Installations consist of a set of components that simultaneously support and control individual behavior. The components are distributed in three layers: a) over the material environment (affordances ${ }^{2}$ ), b) the subject (embodied competences) and c) the social space (institutions ${ }^{3}$, enacted and enforced by other subjects). These components assemble at the time and place the activity is performed.

Installations channel individual behavior. The affordances provide feedforward and feedback. Representations and other embodied skills allow the subject to interpret the objects and the situation. Finally social feed-back funnels behavior into what is expected: proper behavior is reinforced by positive feed-back while improper behavior is extinguished by negative feed-back. Through the social feed-back (and also the outcome of behavior), operant conditioning takes place which facilitates embodiment of "what should be done in such situations". For a detailed description, see (Lahlou, 2017).

Let us take a simple example: when you take the train, from the moment you enter the station to the moment you step out of your destination station on arrival, you take very few personal decisions: your behavior is channeled by a series of successive installations that guide and constrain your actions. You follow the flow. You still have some choices (which train, which car, which seat), but they are socially constructed. Affordances limit your options: you can only use the doors, tracks and seats provided. Then again you are limited by conventions (you must sit on your assigned seat, otherwise someone will ask you to do so). You have some freedom of action as you seat, but you are mostly supposed to seat quietly. Etc. In the end, you behave "properly" as a train passenger. Installations channel behaviors by two complementary mechanisms: constructive and restrictive. In a constructive manner, they offer, suggest and support specific behaviors. In a restrictive manner, they prevent some behaviors and repress those considered inappropriate. This ensures that everyone behaves as expected, a condition for cooperation. Cooperation is essential in a society, and social representations are a major instrument for cooperation (Lahlou, 2001). Most peculiar is this installation makes everyone behave properly, in a similar fashion that fits the cultural script of travelling by train", whatever their age, gender, nationality, religion, social status, personality etc. Therefore, we can see installations can supersede all classic social, psychological, or economic variables. That is how installations manage to homogenize representations in a population.

2 "Roughly, the affordances of things are what they furnish, for good or bad, which is what they afford the observer. ...they are ecological, in the sense that they are properties of the environment relative to an animal. <...> Affordances do not cause behavior but constrain or control it" (Gibson, 1982).

3 "[An institution is] a cluster of social usages. It connotes a way of thought or action of some prevalence and permanence, which is embedded in the habits of a group or the customs of a people. ... The function of each is to set a pattern of behavior and to fix a zone of tolerance for an activity or a complement of activities" (Hamilton, 1932). 
Note that IRs are embodied competences about a specific Object. Therefore, they are part of installations, they are a component of the embodied layer.

The three layers of installations (affordances of the material environment, embodied competences in the subject, and social regulation by institutions) each limit and constrain behavior and leave open only some pathways. As the three layers act simultaneously, the paths that behavior can take are the ones that are compatible with each of the three layers (what is possible, what is thinkable, and what is allowed), which leaves only a rather narrow set of possibilities. Furthermore, the redundancy of the layers of determination makes installations very resilient. The resilience comes from the redundant combination of the constraining power of the three layers of their components. Where one layer of determination fails to scaffold and control, others may repair. For example, if in the train you sit by error in the wrong car, someone will likely tell you and point you to the right seat, as also indicated on your ticket. This means that where the embodied layer fails, the physical layer (affordances) and the social layer (social feed-back) may kick-in and repair.

There are many types of social regulation that produce embodiment of skills that are conform to social expectation: Role and status, Imitation, Conformity and zeal, Seeking guidance, Instruction and guidance, Influence and persuasion, Vigilante effect, Force and threat (Lahlou, 2017. Pp. 132-159). For a detailed description of how installations construct and reconstruct through practice embodied competences in general and representations in particular, refer to (Lahlou, 2017. Pp. 175-289). In short, installations produce similar individual experience, and hence similar IRs. This similarity is reinforced by communication, often prepared by education and training. And in return, the representations contribute to rebuild the installation and the Object, in a chicken-and-egg manner. I have no space to discuss further that point here.

Individuals learn their IRs through practice. The IR of an Object is built by the various types of experiences connected to that Object (e.g. one will learn about Democracy through experiences of votes, collegial discussions, elections etc.) For many aspects of social life, practice is channeled by installations. So most these experiences about the Object tend to be channeled by installations; hence the IR of an Object tends to be constructed by the series of relevant installations present in a culture. Because installations are resilient, they induce similar behavior in all individuals that use them (e.g. all students will get similar experience of Studying because schools are similar). Of course, education and communication, through vicariant experience and stories, contribute to organize individual experience into similar frameworks and to enshrine them into common language and discourse; but the connection between representation and practice is usually formatted by installations and within practice inside in installations. In this perspective, installations are a distributed formatting system for representation and practice that imprints similar IR into the members of a given Population.

So, in large scale societies, installations are similar across a society (schools, airports, etc. are similar across the territory used by the Population). By using these installations, members of a Population are channeled into standard behaviors, 
and therefore they get similar experience, embodied through operant conditioning, and hence they embody similar IR.

The embodied aspect of representations is essential for practice because practice is the articulation of the individual representation in situation, and this articulation combines components of the bodily support with components of the context (Lahlou, 1998. Pp. 69-83). In this movement, the subject extracts from the environment components that match her motives and enacts a behavior stemming from her representations but adapted to the affordances of the situation. E.g., a hungry European subject will eat an apple or a sandwich, depending on what is available; but not a live slug, even though that may be comestible, because a slug does not match the social representation of "food" in that Culture. The reaction of disgust coming from the bodily medium, as well as the sensation of hunger, coming from the same, are essential in such process.

More generally the consideration of the support medium of the representation is essential to the understanding of the functioning of the representation because the nature of the medium does condition the transformation of the structure into a process.

For such considerations, the theory of the medium ("théorie du support") by Bachimont comes handy. It states that (Bachimont, 2004):

- knowledge is the ability to carry out an action for a given purpose (p. 65);

- all knowledge is in its genesis the interpretation and manipulation of a material medium (p. 63);

- the material properties of the inscription medium condition the intelligibility of the inscription (p. 78);

- a thought is a reformulation carried out by the consciousness on the bodily medium which is the body-subject (p. 77).

For example, the notion of "mute zone" of representations comes from the fact that there are, in the same bodily medium that hosts the IR of concern, other IR and cognitive processes that condition and filter the expression of the representation in each situation. As actions are executed by individuals, and not by a population, the relevant unit of analysis for the transformation of representations into action and vice-versa is the individual, as that is the unit inscription of representation and ascription of agency, rather than the Population. And at this point, using epistemically correct definitions of representations, whether IR or SR, is essential.

\section{Conclusion}

A social representation (SR) is a set of individual representations (IRs) of an Object by members of a Population of subjects who deal with this Object. These IRs are similar, and that similarity supports the intersubjective understanding of objects that characterizes a culture. SR are usually described in intension by listing commonalities of the elements of the set (IRs).

What makes the set a social representation is not merely the similarity of IRs, but rather the relation of the Population to the Object of the SR, for which the SR is a functional, constructive instrument. 
The similarity of IRs in a population is constructed by education and communication, which homogenize IRs, but also by individual practice in relation to the Object. In large scale societies, practice is channeled by "installations", local combinations of components that scaffold and control behavior and experience into standard paths of action. Members of a culture behave through similar installations. This generalized channeling of practice constructs similar experiences across the members of a Population, and therefore contributes to members of a given culture having similar IRs.

This epistemic clarification has minor implication on the classic methods of investigation of SRs, which in practice operate by extracting similarities from a sample of IRs to construct definitions in intension of the SR. That is fortunate because it means we do not need to throw away the thousands of empirical papers using social representations theory.

But this clarification has major theoretical implications for the study of the relation between representation and action. That is because the locus of interpretation of situations and of agency is the individual subject, not the Population. Therefore embodiment of an IR in a human body, with the physiological and emotional aspects of that medium must be taken into account, as well as the coexistence and combination within the body of that specific IR with other IRs and more generally with a vast array of cognitive processes. This issue of the nature of the location of the representation will become more and more relevant as representations get inscribed in more media empowered with agency, such as robots and other artificial agents.

\section{References}

Abric, J.-C. (1993). Central system, peripheral system: Their functions and roles in the dynamics of social representations. Papers on Social Representations, 2, 75-78.

Abric, J.-C. (1994). Pratiques sociales et représentations. PUF.

Abric, J.-C. (2003a). La recherche du noyau central et de la zone muette d'étude des représentations sociales. Méthodes d'étude des représentations sociales (pp. 59-80). ERES.

Abric, J.-C. (2003b). Méthodes d'étude des représentations sociales. ERES. Retrieved January 14, 2021, from http://www.cairn.info/methodes-d-etude-des-representationssociales--9782749201238.htm

Bachimont, B. (2004). Arts et sciences du numérique: Ingénierie des connaissances et critique de la raison computationnelle [Université de Technologie de Compiègne]. In Mémoire de HDR. Retrieved January 20, 2021, from http://scholar.google.fr/scholar?hl=fr\&q=bachimont\&btnG=Rechercher\&lr=\&as_ylo= \&as vis $=0 \# 1$

Barker, R.G. (1968). Ecological psychology: Concepts and methods for studying the environment of human behavior. Stanford University Press.

Barsalou, L.W. (2003). Abstraction in perceptual symbol systems. Philosophical Transactions: Biological Sciences, 358(1435), 1177-1187. https://doi.org/10.1098/rstb.2003.1319

Berger, P.L., \& Luckmann, T. (1966). The social construction of reality; a treatise in the sociology of knowledge (1st ed.). Doubleday.

Billig, M. (1988). Social representations, objectification and anchoring: A rhetorical analysis. Social Behaviour, 3, 1-16.

Bourdieu, P., \& Passeron, J.-C. (1977). Reproduction in Education, Society and Culture [1st ed. in French 1970]. Reproduction: In Education, Society and Culture (2nd ed.). Sage.

Bruner, J.S. (1999). The Process of Education (25th ed.). Harvard University Press. https://doi.org/10.1073/pnas.0703993104 
Cantor, G. (1874). Ueber eine Eigenschaft des Inbegriffs aller reellen algebraischen Zahlen ("On a Property of the Collection of All Real Algebraic Numbers"). Journal Für Die Reine Und Angewandte Mathematik, 77, 258-226.

Cicourel, A.V. (1992). The interpenetration of communicative contexts: Examples from medical encounters. In A. Duranti \& C. Goodwin (Eds.), Rethinking Context (vol. 50, issue 2, pp. 291-311). Cambridge University Press.

Codol, J.-P. (1969). Note terminologique sur l'emploi de quelques expressions concernant les activités et processus cognitifs en psychologie sociale. Bulletin de Psychologie Sociale, 23, 63-71.

Dawkins, R. (1976). The selfish gene. Oxford University Press. Retrieved February 15, 2021, from https://catalogue.lse.ac.uk/Record/20995

Doise, W. (1986). Les représentations sociales : Définition d'un concept. In W. Doise \& A. Palmonari (Eds.), L'étude des représentations sociales. Textes de base en Psychologie (pp. 81-94). Delachaux et Niestlé.

Doise, W., \& Palmonari, A. (1986). Caractéristiques des représentations sociales. In W. Doise \& A. Palmonari (Eds.), L'étude des représentations sociales. Textes de base en Psychologie (pp. 12-33). Delachaux et Niestlé.

Durkheim, E. (1898). Représentations individuelles et représentations collectives. Revue de Métaphysique et de Morale, 6, 273-302.

Duveen, G., \& Lloyd, B.B. (1990). A semiotic analysis of the development of social representations of gender. In G. Duveen \& B.B. Lloyd (Eds.), Social Representations and the Development of Knowledge (pp. 27-46). Cambridge University Press.

Farr, R. (1987). Social representations: A French tradition of research. Journal for the Theory of Social Behaviour, 17(4), 343-365. https://doi.org/10.1111/j.1468-5914.1987.tb00103.x

Flament, C. (1994). Structure, dynamique et transformation des représentations sociales. In J.-C. Abric (Ed.), Pratiques sociales et représentations (pp. 37-57). PUF.

Foucault, M. (1978). Discipline and Punish: The Birth of the Prison (vol. 7, issue 5). https://doi.org/10.2307/2065008

Freud, S. (1895). Project for a scientific psychology. In J. Strachey, A. Freud, A. Tyson, \& A. Strachey (Eds.), The Standard Edition of the Complete Psychological Works of Sigmund Freud. Vol. I. 1886-1899 (pp. 283-398). Vintage [reprint 1999].

Gibson, J.J. (1982). Notes on affordances (Unpublished manuscript, 1967). In E. Reed \& R. Jones (Eds.), Reasons for Realism. Selected Essays of James J. Gibson (pp. 401-418). Lawrence Erlbaum Associates.

Giddens, A. (1984). The constitution of society: Outline of the theory of structuration. University of California Press.

Goffman, E. (1974). Frame analysis: An essay on the organization of experience. Harper \& Row.

Halmos, P.R. (1974). Naive set theory (1st ed. 1960). Springer Science + Business Media, LLC. https://doi.org/10.1007/978-1-4757-1645-0

Hamilton, W.H. (1932). Institution. In E.R.A. Seligman \& A. Johnson (Eds.), Encyclopaedia of the Social Sciences (vol. 8, pp. 84-89). Macmillan. Retrieved December 11, 2020, from https://archive.org/stream/encyclopaediaoft030467mbp/encyclopaediaoft030467mbp_djvu.txt

Harré, R. (1984). Some reflections on the concept of "social representation." Social Research, 51(4, Winter), 927-938.

Herzlich, C. (1969). Santé et maladie, analyse d'une représentation sociale. Mouton.

Hutchins, E.L. (1995). Cognition in the Wild. MIT Press.

Jahoda, G. (1988). Critical notes and reflections on 'social representations.' European Journal of Social Psychology, 18(3), 195-209. https://doi.org/10.1002/ejsp.2420180302

Jodelet, D. (1989a). Les représentations sociales: un domaine en expansion. In D. Jodelet (Ed.), Les représentations sociales (pp. 31-61). Presses Universitaires de France.

Jodelet, D. (1989b). Les Représentations Sociales. Presses Universitaires de France.

Jodelet, D. (1991). Madness and social representations: Living with the mad in one French community (1st ed. French 1989). University of California Press. Retrieved January 24, 2021, from http://books.google.com.co/books/about/Madness_and_Social_Representations.html?id=MZYe iEeQVjUC\&redir_esc=y 
Johnson-Laird, P.N. (1983). Mental models: Towards a cognitive science of language, inference, and consciousness. Cambridge University Press.

Karmiloff-Smith, A. (1992). Beyond modularity. A developmental perspective on cognitive science. MIT Press.

Lahlou, S. (1996). The propagation of social representations. Journal for the Theory of Social Behaviour, 26(2), 157-175. https://doi.org/10.1111/j.1468-5914.1996.tb00527.x

Lahlou, S. (1998). Penser manger : Alimentation et représentations sociales. P.U.F. Retrieved January 29, 2021, from https://catalogue.1se.ac.uk/Record/526701

Lahlou, S. (2001). Functional aspects of social representations. In K. Deaux \& G. Philogene (Eds.), Representations of the social: Bridging theoretical traditions (pp. 131-146). Blackwell.

Lahlou, S. (2006). L'activité du point de vue de l'acteur et la question de l'inter-subjectivité : huit années d'expériences avec des caméras miniaturisées fixées au front des acteurs (subcam). Communications, 80, 209-234.

Lahlou, S. (2015). Social representations and social construction: the evolutionary perspective of installation theory. In G. Sammut, E. Andreouli, G. Gaskell, \& J. Valsiner (Eds.), Handbook of Social Representations (pp. 193-209). Cambridge University Press. https://doi.org/10.1017/CBO9781107323650.017

Lahlou, S. (2017). Installation theory: The societal construction and regulation of behaviour. In Installation Theory: The Societal Construction and Regulation of Behaviour. Cambridge University Press. https://doi.org/10.1017/9781316480922

Lahlou, S., \& Abric, J.-C. (2011). What are the "elements" of a representation? Papers on Social Representations, 20, 20.1-20.10.

Lashley, K. (1951). The problem of serial order in behavior. In L.A. Jeffress (Ed.), Cerebral Mechanisms in Behavior: The Hixon Symposium (issue 7, pp. 112-146). Wiley. https://doi.org/10.1093/rfs/hhq153

Lheureux, F., Rateau, P., \& Guimelli, C. (2008). Hiérarchie structurale, conditionnalité et normativité des représentations sociales. Les Cahiers Internationaux de Psychologie Sociale, 77, 41-55.

Maturana, H.R., \& Varela, F.J. (1980). Autopoiesis and Cognition. The Realization of the Living (p. 141). D. Reidel Publishing Company.

McKinlay, A., \& Potter, J. (1987). Social representations: A conceptual critique. Journal for the Theory of Social Behaviour, 17(4), 471-487. https://doi.org/10.1111/j.1468-5914.1987.tb00109.x

Mead, G.H. (1972). Mind, Self, and Society from the standpoint of a social behaviourist (1st ed 1934). University of Chicago Press.

Moliner, P. (1993). ISA : L'induction par scénario ambigu. Une méthode pour l'étude des représentations sociales. Revue Internationale de Psychologie Sociale, 2, 7-21.

Moscovici, S. (1961). La psychanalyse, son image et son public. Etude sur la représentation sociale de la psychanalyse. Presses Universitaires de France.

Moscovici, S. (1976). La psychanalyse son image et son public. PUF.

Moscovici, S. (1988). Notes towards a description of social representations. European Journal of Social Psychology, 18, 211-250. https://doi.org/10.1002/ejsp.2420180303

Pea, R.D. (1993). Practices of distributed intelligence and designs for education. In G. Salomon (Ed.), Distributed Cognitions. Psychological and Educational Considerations (pp. 47-87). Cambridge University Press. Retrieved February 10, 2021, from http://books.google.com/books?id=m8Yna0cjxAgC\&pgis=1

Potter, J., \& Edwards, D. (1999). Social representations and discursive psychology: From cognition to action. Culture \& Psychology, 5(4), 447-458. https://doi.org/10.1177/1354067X9954004

Potter, J., \& Litton, I. (1985). Some problems underlying the theory of social representations. British Journal of Social Psychology, 24(2), 81-90. https://doi.org/10.1111/j.20448309.1985.tb00664.x

Potter, J., \& Wetherell, M. (1987). Discourse and social psychology: Beyond attitudes and behaviour. Sage.

Rogoff, B. (2003). The cultural nature of human development. Oxford University Press.

Rosenthal, R. (1966). Experimenter effects in behavioural research. Appleton, Century-Crofts. 
Runde, V. (2005). Set theory. In A Taste of Topology (pp. 5-22). Springer-Verlag. https://doi.org/10.1007/0-387-28387-0

Russell, B. (1908). Mathematical logic as based on the theory of types. American Journal of Mathematics, 30(3), 222. https://doi.org/10.2307/2369948

Schütz, A. (1944). The stranger : An essay in social psychology. The American Journal of Sociology, 49(6), 499-507.

Sperber, D. (1996). La contagion des idées. Odile Jacob.

Suchman, L.A. (1987). Plans and situated actions. The problem of human-machine communication. Cambridge University Press.

Vygotsky, L.S. (1986). Thought and language (p. 287). MIT Press.

Whitehead, A.N., \& Russell, B. (1962). Principia mathematica (2nd ed.). Cambridge University Press.

\title{
Article history:
}

Received: 1 March 2021

Revised: 10 April 2021

Accepted: 10 May 2021

\section{For citation:}

Lahlou, S. (2021). Social representations and individual representations: What is the difference? And why are individual representations similar? RUDN Journal of Psychology and Pedagogics, 18(2), 315-331. http://dx.doi.org/10.22363/2313-1683-2021-18-2-315-331

\section{Bio note:}

Saadi Lahlou, Ph.D., HDR, is Professor in Social Psychology at the Department of Psychological and Behavioural Science, the London School of Economics (London, United Kingdom). Since 2018, he is the Director of the Paris Institute for Advanced Study (Paris, France). He obtained his $\mathrm{PhD}$ in social psychology at Ecole des Hautes Etudes en Sciences Sociales (Paris) with Pr. Serge Moscovici, and his HDR (habilitation as a research director) at University of Provence with Pr. Jean-Claude Abric. He also holds degrees in Human Biology and Ethology. He conducts and publishes research in the areas of social psychology, consumer behaviour, survey and forecast methods, lexical analysis, cognition and design. E-mail: S.Lahlou@lse.ac.uk

DOI 10.22363/2313-1683-2021-18-2-315-331

Теоретическая статья

\section{Социальные представления \\ и индивидуальные представления: в чем разница? И почему индивидуальные представления похожи?}

\author{
С. Лалу \\ Лондонская школа экономики и политических наук, \\ Соединенное Королевство Великобритании и Северной Ирландии, \\ WC2A 2AE, Лондон, Houghton St \\ Парижский институт перспективных исследований, \\ Франиузская Республика, 75004, Париж, Quаi d'Anjou, д. 17
}

$\checkmark$ S.Lahlou@lse.ac.uk

\begin{abstract}
Аннотация. Проясняется давняя двусмысленность в толковании понятия социальных представлений и дается четкое операциональное определение отношения между «социальным представлением»и «индивидуальным представлением». Это определение, основанное на теории множеств, поддерживает большинство современных эм-
\end{abstract}


пирических методов исследования социальных представлений. Другими словами, социальное представление объекта в популяции - это математический набор индивидуальных представлений, которые индивиды данной популяции имеют относительно этого объекта. Компоненты представления трактуются как компоненты, используемые для описания этого множества в математическом смысле данного термина. Статистические методы, как и метод контент-анализа, могут создавать такие компоненты путем сравнения индивидуальных представлений для извлечения общих черт, и именно этому посвящены классические исследования социальных представлений. Предлагается ответ на вопрос: как получилось, что в конкретной культуре индивиды имеют индивидуальные представления, похожие друг на друга?

Ключевые слова: социальные представления, индивидуальные представления, теория инсталляции, интерсубъективное понимание объекта

\section{История статьи:}

Поступила в редакцию: 1 марта 2021 г.

Принята к печати: 10 мая 2021 г.

\section{Для цитирования:}

Lahlou S. Social representations and individual representations: what is the difference? And why are individual representations similar? // Вестник Российского университета дружбы народов. Серия: Психология и педагогика. 2021. Т. 18. № 2. С. 315-331. http://dx.doi.org/10.22363/2313-1683-2021-18-2-315-331

\section{Сведения об авторе:}

Лалу Саaди, Ph.D., HDR, профессор социальной психологии департамента психологии и поведенческих наук Лондонской школы экономики и политических наук (Лондон, Великобритания). С 2018 года является директором Парижского института перспективных исследований (Париж, Франция). Получил докторскую степень по социальной психологии в Высшей школе социальных наук под руководством профессора Сержа Московиси и квалификацию руководителя исследований (HDR) в Университете Прованса под руководством профессора Жана-Клода Абрика. Имеет ученые степени в области биологии и этологии человека. Проводит и публикует исследования в области социальной психологии, поведения потребителей, методологии опросов и прогнозов, лексического анализа, познания и дизайна. E-mail: S.Lahlou@1se.ac.uk 